\title{
Letramento Racial Crítico na construção da Educação Antirracista nas aulas de língua inglesa da Educação Básica
}

\section{Critical Racial Literacy to construct Antiracist Education in Basic Education English classes}

\section{Alfabetización Racial Crítica en la construcción de una educación antirracista en las clases de inglés en Educación Básica}

\author{
Cecilia Gusson Santos ${ }^{1}$ \\ https://orcid.org/0000-0001-9195-3701 \\ James Rios de Oliveira Santos ${ }^{2}$ \\ Michele Salles El Kadri ${ }^{3}$ \\ (i) https://orcid.org/0000-0003-3017-9921 \\ https://orcid.org/0000-0002-5836-4988
}

\begin{abstract}
RESUMO: Este artigo tem por objetivo principal apresentar uma proposição de ação/intervenção, por meio do Letramento Racial Crítico (FERREIRA, 2014), com intuito de viabilizar um trabalho pedagógico que assegure os pressupostos da Educação Antirracista. Desse modo, as bases teóricas são sustentadas pelos conceitos da Análise do Discurso Crítica (ADC) (FAIRCLOUGH, 2001), visando analisar e compreender a relação dialética entre discurso e sociedade, por meio das práticas sociais e discursivas construídas pelas manifestações do movimento Black Lives Matter e seus efeitos sociais. Assim, esta proposta se articula com os princípios da Educação Antirracista e do Letramento Racial Crítico discutidos por Cavalleiro (2001), Ferreira (2012, 2014, 2015) e Pereira e Lacerda (2019), de modo a promover o reconhecimento e mecanismos de (re)construção da identidade racial negra no contexto escolar, assim como fomentar ações de combate ao racismo estrutural e institucional (ALMEIDA, 2017). Este escrito é relevante na medida em que se observa uma lacuna nas produções sobre a identidade racial no Brasil e em propostas que promovem a Educação Antirracista, principalmente, na Educação Básica.
\end{abstract}

PALAVRAS-CHAVE: Educação Antirracista. Letramento Racial Crítico. Análise do Discurso

\footnotetext{
1Professora de inglês da educação básica, Doutoranda em Estudos da Linguagem pelo Programa de Pós-Graduação da Universidade Estadual de Londrina (PPGEL/UEL). E-mail: cecilia.gusson@uel.br

${ }^{2}$ Diretor de Cultura da Universidade Estadual do Norte do Paraná (UENP), doutorando em Estudos Literários pela Universidade Estadual de Londrina (UEL).E-mail: james@uenp.edu.br

${ }^{3}$ Professora Adjunta da Universidade Estadual de Londrina (UEL). Pós-Doutora em Linguística Aplicada pela Unicamp e Pós-doutorado em Educação pela UFES (em andamento). Doutora em Estudos da Linguagem (UEL) com estágio de doutorado-sandwich na Griffith University, Austrália. E-mail: misalles@uel.br
} 
Crítica.

ABSTRACT: This article aims to present a proposition of action/intervention, through Critical Racial Literacy (FERREIRA, 2014), in order to enable pedagogical work that ensures the assumptions of Antiracist Education. Thus, the theoretical bases are supported by the concepts of Critical Discourse Analysis (CDA) (FAIRCLOUGH, 2001), with the goal to analyze and understand the dialectical relationship between discourse and society, through social and discursive practices produced by the manifestations of the movement Black Lives Matter and its social effects.Thus, the proposal is articulated with the principles of Antiracist Education and Critical Racial Literacy discussed by Cavalleiro (2001), Ferreira (2012, 2014, 2015) and Pereira and Lacerda (2019), in order to promote the recognition and mechanisms of (re)construction of black racial identity in the school context, as well as to promote actions to combat structural and institutional racism (ALMEIDA, 2017). This writing is relevant because there is a gap in the productions on racial identity in Brazil and in proposals that promote Anti-racist Education, mainly in Basic Education.

KEYWORDS: Antiracist Education. Critical Racial Literacy. Critical Discourse Analysis.

RESUMEN: El objetivo principal de este artículo es presentar una propuesta de acción/intervención, a través de la Alfabetización Racial Crítica (FERREIRA, 2014), con el fin de posibilitar un trabajo pedagógico que asegure los supuestos de la Educación Antirracista. Así, las bases teóricas se sustentan en los conceptos de Análisis Crítico del Discurso (ACD) (FAIRCLOUGH, 2001), con el objetivo de analizar y comprender la relación dialéctica entre discurso y sociedad, a través de prácticas sociales y discursivas construidas por las manifestaciones del movimiento Black Lives Matter y sus efectos sociales. Así, esta propuesta se articula con los principios de Educación Antirracista y Alfabetización Racial Crítica discutidos por Cavalleiro (2001), Ferreira $(2012,2014,2015)$ y Pereira y Lacerda (2019), con el fin de promover el reconocimiento y los mecanismos de (re) construcción de la identidad racial negra en el contexto escolar, así como promover acciones para combatir el racismo estructural e institucional (ALMEIDA, 2017). Este escrito es relevante en la medida en que existe un vacío en las producciones sobre identidad racial en Brasil y en propuestas que promueven la Educación Antirracista, principalmente en la Educación Básica.

PALABRAS CLAVE: Educación Antirracista. Alfabetización Racial Crítica. Análisis Crítico del Discurso.

\section{Introdução}

A problematização das relações étnico-raciais no Brasil é sempre marcada por conflitos. Com raízes profundas, o racismo estrutural, ao encontrar seu fundamento assentado no mito da democracia racial ${ }^{4}$, atravessa quase todas as esferas da atividade humana, sobretudo, no contexto escolar, tornando-se um desafio ao trabalho docente.

\footnotetext{
${ }^{4}$ Nascimento (2019), ao tratar da "democracia racial brasileira", assevera que ela é a metáfora perfeita para designar o racismo à brasileira: "[...] não tão obvio quanto o dos Estados Unidos e nem legalizado qual o apartheid da África do Sul, mas institucionalizado de forma eficaz nos níveis oficiais do governo, assim como difuso e profundamente penetrante no tecido social." (NASCIMENTO, 2019, p. 111).
} 
Diante desse cenário, este artigo objetiva apresentar uma proposição de ação/intervenção, por meio do Letramento Racial Crítico (FERREIRA, 2014), com intuito de viabilizar um trabalho pedagógico que possibite a construção de uma Educação Antirracista, sustentada pela perspectiva da Análise do Discurso Crítica (doravante ADC) (FAIRCLOUGH, 2001).

Aulas de línguas também têm a responsabilidade de trazer temas que promovam a desconstrução de estereótipos e desigualdades sociais implicados pelos termos de raça e etnia (FERREIRA, 2007). Leffa (2008) pontua que como professores/as "transmitimos valores políticos não só pelo que fazemos, mas também pelo que somos" (LEFFA, 2008, p. 373-374). Como agentes de mudança social, eles/as devem promover condições para que os/as estudantes aprendam que o desenvolvimento - individual, da comunidade e do país - depende da habilidade em conduzir negociações nas novas relações de poder que se estabelecem com o uso da língua estrangeira (LEFFA, 2008).

Nesse contexto, a Educação Antirracista emerge como uma necessidade e uma urgência para abarcar situações de racismo presentes na sociedade e consequentemente no contexto escolar, instrumentalizando professores/as e estudantes para lidar com essas questões tão logo elas sejam identificadas nos discursos presentes no cotidiano da escola.

Segundo Cavalleiro (2001), a Educação Antirracista tem como princípios: o reconhecimento da existência do problema racial na sociedade brasileira; a busca permanente por espaços de reflexão sobre o racismo e seus derivados no contexto escolar; o repúdio e a intervenção a qualquer atitude preconceituosa e discriminatória na sociedade e no espaço escolar e o cuidado para que as relações entre negros e brancos (crianças e adultos) sejam respeitosas; promoção da igualdade por meio do reconhecimento e valorização da diversidade do contexto escolar, encorajando a participação de todos os atores sociais; ensino crítico da história dos diferentes grupos sociais, étnicos e raciais que constituem a história brasileira; busca de materiais que promovam a ruptura com o eurocentrismo dos currículos escolares, materiais didáticos e práticas de ensino e que, além disso, promovam a diversidade racial, assim como o estudo da história e cultura do povo negro; pensar meios de educar para o reconhecimento positivo da diversidade racial; e, por fim, elaborar ações que possibilitem o fortalecimento do auto-conceito de alunos e alunas pertencentes a grupos discriminados.

Incluímos ainda o princípio do reconhecimento e construção da identidade racial de estudantes negros/as em consonância com os valores do povo negro, por meio de 
representações justas e críticas de como essa população foi e é fundamental para o desenvolvimento da sociedade brasileira. Essas identidades raciais negras devem ter condições de desenvolvimento não pela perspectiva do branco (eurocentrista), não pelo racismo e por estereótipos e discursos que inferiorizam o povo negro, mas pelo importante aporte histórico e social que a negritude representa e que, por muito tempo, foi silenciado.

Contudo, há carência de materiais mediadores e oportunidades que permitam aos alunos/as se tornarem conscientes das ideologias dominantes, identificarem as situações de opressão e que permitam o desenvolvimento de análise de linguagem para agir em prol da equidade racial. Acreditamos que seja necessário desenvolver habilidades, capacidades e ferramentas linguísticas para a atuação na sociedade. Por esse viés, o presente artigo pretende lançar uma reflexão sobre o tema com vistas a contribuir com os processos de desconstrução de estigmas e estereótipos e, quem sabe, possibilitar o reencontro dos atores educacionais com suas respectivas identidades raciais.

Ferreira e Barbosa (2019) ressaltam que para que professores/as críticos lidem com as questões raciais, requer consciência sobre suas próprias trajetórias e que, no Brasil, o processo de reconhecimento da sua própria identidade racial é algo muito complexo, justamente pelo racismo mascarado e a constante falta de representatividade da população negra em vários espaços sociais, inclusive na escola. Assim, na esteira da Educação Antirracista, inicialmente, é essencial tratar a aprendizagem e o reconhecimento da identidade racial de professores/as, para que a criticidade racial seja desenvolvida e, consequentemente, as condições para que esse professor ou professora possa intervir em sua realidade.

Destarte, conduziram a discussão as vozes dos autores Fairclough (2001, 2003, 2009) e Wodak (2004), da Análise do Discurso Crítica (ADC), e de Ferreira (2007, 2014, 2015), do Letramento Racial Crítico, para compreender os efeitos sociais do Movimento Black Lives Matter, manifestados por meio das práticas discursivas.

O movimento Black Lives Matter nasceu em 2013, apenas como uma hashtag, depois que o vigilante de bairro civil, George Zimmerman, foi inocentado pela morte a tiros do adolescente negro, Trayvon Martin, em fevereiro de 2012, na Flórida. Foi concebido por três mulheres negras: Alicia Garza (Los Angeles, 1981), Patrisse Cullors (Los Angeles, 1984) e Opal Tometi (Phoenix, Arizona, 1984). Em 2014, o movimento começou a ter relevância nacional em outro caso de violência policial. Em 2020, a hashtag 
voltou a invadir as redes sociais, com o assassinato de George Floyd, que levou as pessoas novamente aos protestos. e fez o movimento eclodir em diversas ações de alcance mundial, colocando em evidência novamente a pauta dos direitos raciais (GUIMÓN, 2020).

Por todo o exposto, acreditamos que esta proposta pode fornecer subsídios para possibilitar o trabalho crítico do/a professor/a de línguas sobre a pauta étnico-racial, pelo viés crítico, desenvolvendo a consciência crítica do aprendiz para interagir e atuar tanto em espaços virtuais de interação como no mundo social real, abarcando os conceitos de transformação social por meio da reflexão (FAIRCLOUGH, 2009) e da conscientização (FREIRE, 1979).

Embora a educação para as relações étnico-raciais, por exemplo, esteja presente nas escolas por força da Lei 10.639/03 (BRASIL, 2003), que estabelece como obrigatório o ensino da história e da cultura afro-brasileira e africana, bem como a inclusão do Dia da Consciência Negra no calendário escolar, entende-se que, além de trazer a temática para as salas de aula e marcar a data de modo pontual no tempo escolar, é necessário desenvolver nos estudantes as capacidades que favoreçam sua participação social, mais especificamente no meio digital, para contrapor discursos opressores. A área de Linguagens é particularmente relevante como instância na qual essas capacidades podem ser desenvolvidas.

Por isso, a proposta deste artigo pretende se configurar como um possível caminho para abordar as questões étnico-raciais na escola, por meio da contextualização histórica, social e teórica que são essenciais para o aprofundamento das discussões e não apenas com alguns eventos culturais isolados que, por vezes, acabam por reproduzir uma identidade racial pela perspectiva do branco, que pouco reforça a representatividade e importância do povo negro para a construção da sociedade brasileira.

Essa questão é significativa e importante para tratar das desigualdades raciais no sistema brasileiro de educação básica, uma vez que a diferença de desempenho entre um/a aluno/a branco/a, negro/a ou pardo/a não é independente da escola que ele/a frequenta. Para Soares e Alves (2003), a diferença poderá ser acentuada ou reduzida, dependendo do ambiente escolar em que os/as alunos/as estão inseridos/as, pois isso, esse estudo nos leva a perceber a necessidade de transformar os ambientes escolares de modo a garantir a inclusão e não a exclusão dos/as alunos/as negros/as e que se propicie 
a identificação dos/as estudantes negros/as com o currículo escolar.

Este artigo está organizado da seguinte maneira: primeiramente, apresentamos o referencial teórico que nos embasa (a ADC e o Letramento Racial Crítico); em seguida, apresentamos a proposta pedagógica com base nesses pressupostos.

\section{Análise do Discurso Crítica}

A análise dos enunciados deste projeto será realizada pelas lentes da Análise do Discurso Crítica (FAIRCLOUGH, 2009). Na esteira dos conceitos da ADC utilizados neste trabalho, destaco a prática social como "as maneiras habituais, em tempos e espaços particulares, pelos quais pessoas implicam recursos - materiais ou simbólicos - para agirem juntas no mundo" (CHOULIARAKI; FAIRCLOUGH, 1999, p. 21).

As práticas sociais e a linguagem têm relação intrínseca. Fairclough (2009) salienta que a relação entre discurso e estrutura social tem natureza dialética e que a constituição discursiva de uma sociedade é produto de uma prática social que está arraigada em estruturas sociais concretas e, assim, orientada para elas. Fairclough (2001) defende o discurso como prática política e ideológica. Como prática política, o discurso estabelece, mantém e transforma as relações de poder e as entidades coletivas em que existem tais relações. Como prática ideológica, o discurso constitui, naturaliza, mantém e também transforma os significados de mundo nas mais diversas possíveis relações de poder. 0 discurso é, então, visto como modo de ação sobre o mundo e a sociedade, ou seja, socialmente constitutivo e constituído socialmente.

Wodak (2004) ressalta que para a ADC a ideologia é vista como um importante aspecto da criação e manutenção das relações desiguais de poder; a ADC tem um interesse particular em como a linguagem medeia a ideologia numa variedade de instituições sociais. A ideologia pode ser vista como o termo utilizado para indicar o estabelecimento e a conservação de relações desiguais de poder. E é, por isso, que a ADC indica, como um de seus objetivos, a desmistificação dos discursos por meio da decifração da ideologia através dos textos. Para a ADC, os textos costumam ser espaços de luta, uma vez que guardam traços de diferentes discursos e ideologias em disputa pelo controle (WODAK, 2004).

Wodak (2004) reforça que o poder não se origina na linguagem, mas que através dela é possível desafiar, manter e até mesmo subverter e alterar o poder. 0 poder não 
somente se efetiva no interior do texto, mas também no controle que uma pessoa é capaz de exercer sobre uma situação social através do texto. E esta relação está explícita na nossa preocupação de como o discurso do futuro professor, a forma como este representa a prática social e como este se vê como agente desta prática pode acirrar representações de poder e ideologia trazidas pelo aprendizado da língua inglesa tanto no seu imaginário quanto nas significações que esta língua pode trazer para os alunos em sala de aula. Isto porque as estruturas de dominação são legitimadas pelas ideologias dos grupos que detêm o poder, e a língua inglesa é hoje um dos maiores representantes destes grupos. Por isso, a ADC oferece uma valiosa contribuição de linguistas para o debate de questões ligadas ao racismo, à discriminação baseada no sexo, raça, ao controle e à manipulação institucional, à violência, à identidade nacional, à autoidentidade e à identidade de gêneros e à exclusão social como um todo (RESENDE; RAMALHO, 2006).

Diante do exposto, esta proposta almeja promover a transformação social por meio da mudança nas práticas discursivas. De acordo com Resende e Ramalho (2006), mudanças em práticas discursivas estabilizadas podem promover mudanças nas práticas sociais, desvelando relações assimétricas de poder sustentadas pelo discurso. Para tanto, utilizaremos os elementos de análise baseados no modelo tridimensional, que engloba Prática Social Investigada, Prática Discursiva, Texto.

Figura 1 - Proposição do Modelo Tridimensional de Chouliaraki e Fairclough (1999)

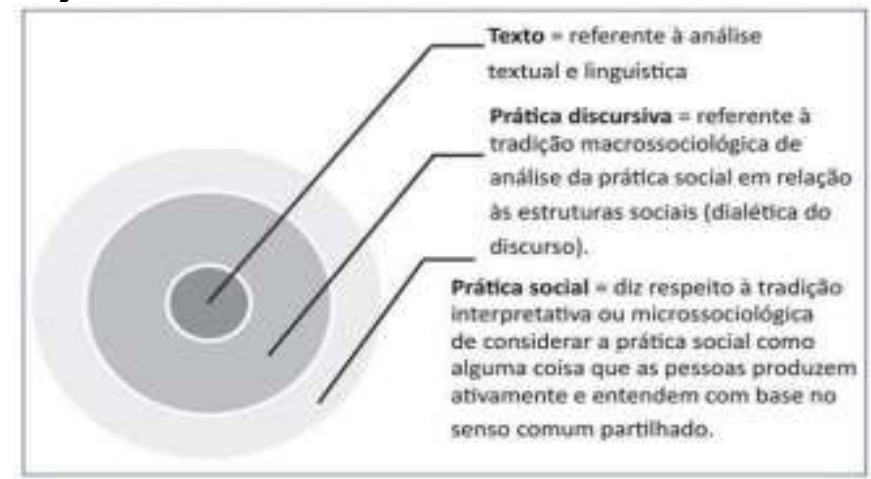

Fonte: Adaptado por Silva e Gonçalves (2017).

O modelo Tridimensional, proposto por Chouliaraki e Fairclough (1999), distingue três dimensões no discurso - texto, prática discursiva e prática social. Por prática discursiva "entende-se os processos de produção, distribuição e consumo do texto" (RESENDE; RAMALHO, 2004, p. 186). A prática discursiva é mediadora entre o texto e a 
prática social. A prática social é carregada de ideologias (sentidos, pressuposições e metáforas) e hegemonia (orientações econômicas, políticas, culturais e ideológicas). Esses processos constituem e deixam marcas no texto (RESENDE; RAMALHO, 2004).

\section{Letramento Racial Crítico}

Para tratar do Letramento Racial Crítico, precisamos contextualizar o conceito de raça, visto que, na organização social os indivíduos são racializados (FERREIRA, 2014). De acordo com Bell (1997), o termo "raça" é uma construção social, um conceito criado pela sociedade e não uma realidade biológica. Ela vem sendo historicamente construída como forma de categorizar as pessoas e, assim, interpretar as diferenças humanas e justificar arranjos socioeconômicos que beneficiam os brancos e marginalizam os negros.

Deste modo, para a autora (BELL, 1997), a raça impacta a vida das pessoas, psicologicamente e materialmente de forma consequente e duradoura, principalmente devido ao racismo, por isso a importância de repensar sobre o racismo estrutural ${ }^{5} \mathrm{e}$ institucional (ALMEIDA, 2017), como eles são reproduzidos sócio-historicamente e podem ser desconstruídos pela transformação das práticas sociais (FAIRCLOUGH, 2003).

Pereira e Lacerda (2019, p. 103) asseveram que escrever sobre raça e racismo é um "tema complexo e controverso, haja vista o discurso de que no Brasil não existe racismo". Com essa afirmação, que demonstra a dificuldade da nossa tarefa, passamos a tratar do Letramento racial crítico como instrumento de transformação social na educação básica.

Mosley (2010) explica que a pedagogia para o Letramento Racial Crítico é um conjunto de ferramentas pedagógicas para praticar o letramento racial em escolas e desafiar ideologias que ensinaram que todos os grupos minoritários têm oportunidades iguais para o sucesso educacional. Para a autora, ensino antirracista se concentra na ruptura de ideologias racistas por meio de discussão e ação, com base numa perspectiva social e histórica de raça e racismo. Além disso, Ferreira (2015, p. 137) define como "uma

\footnotetext{
${ }^{5}$ Racismo estrutural é a formalização de um conjunto de práticas institucionais, históricas, culturais e interpessoais dentro de uma sociedade que frequentemente coloca um grupo social ou étnico em uma posição melhor para ter sucesso e ao mesmo tempo prejudica outros grupos de modo consistente e constante causando disparidades que se desenvolvem entre os grupos ao longo de um período de tempo (ALMEIDA, 2017).
} 
corrente de letramentos que se propõe a estudar e entender como as relações de poder são engendradas para modelar as identidades de raça e como essas identidades atuam no seio das sociedades." Assim, o estudo do Letramento Racial Crítico

[...] Pode contribuir para o surgimento de identidades mais comprometidas com a superação histórica das desvantagens, à medida que os indivíduos entendem o funcionamento das relações de poder e dos discursos, aprendem a respeitar sua história, identidade e coletivamente buscam meios para que uma sociedade mais justa e igualitária seja possível. (PEREIRA; LACERDA, 2019, p. 103)

Dessa maneira, para esta proposta, consideram-se os seguintes elementos do Letramento Racial Crítico e da Educação Antirracista elencados no Quadro 1 - Princípios para a elaboração de materiais para a Educação Antirracista.

$\mathrm{Na}$ esteira da naturalização de estruturas socializadas que representam a classe dominante, em que a história é sempre contada do lugar de fala (RIBEIRO, 2017) do branco, sendo a voz do negro historicamente silenciada, pois "[...] o silenciamento é o produto da ação do discurso hegemônico da identidade branca, que ao ser massivamente repetido, passa a ser verdadeiro" (PEREIRA; LACERDA, 2019, p. 104).

Nessa tessitura, Gonçalves (1985) reverbera que muito do que realmente deve ser problematizado acaba ficando de fora das discussões no contexto escolar, cedendo espaço para manifestações rasas sobre a cultura dos povos africanos. Por esse viés, as práticas pedagógicas continuarão silenciando a criança negra. Por isso, debater, planejar e reconstruir o que se entende pauta étnico-racial, normalmente discutida apenas no mês de novembro, Mês da Consciência Negra, na prática escolar, é dar voz à comunidade negra da escola e fomentar reflexões sobre as questões da negritude e da branquitude (GONÇALVES, 1985).

Afirmamos que utilizamos o termo "branquitude"6, segundo Piza (2005), referindose à identidade racial branca para tratar da visão desse grupo com relação ao movimento social Black Lives Matter. Já como "negritude" 7, compreendemos a "afirmação das identidades negras" (PIZA, 2005, p. 7) e, por essa perspectiva, a visão dos alunos/as

\footnotetext{
6 "[...] Ser branco significa, portanto, ser a norma, o ponto de referência para se construir a alteridade diante do outro, do não branco. Em outras palavras, a branquitude significou, num primeiro momento, a não consciência da pessoa branca perante a situação de privilégios em uma sociedade marcada por séculos de escravidão negra." (PIZA, 2005, p. 7).

7 "[...] Um dos objetivos fundamentais da negritude era a afirmação e a reabilitação da identidade cultural, da personalidade própria dos negros".
} 
negros/as das turmas em que o trabalho será desenvolvido. Explanamos essas terminologias para embasar a compreensão de um terceiro espaço (BABHA, 1990) de aprendizagem, marcado pela intersecção dessas visões, conforme ilustrado na imagem abaixo:

Figura 2 - Criação do Terceiro Espaço - Intersecção das visões da branquitude e da negritude

\section{Terceiro Espaço}

Compartithamento de Vivências, Experiências e Ideias por meio dos espaços de discussäo criados

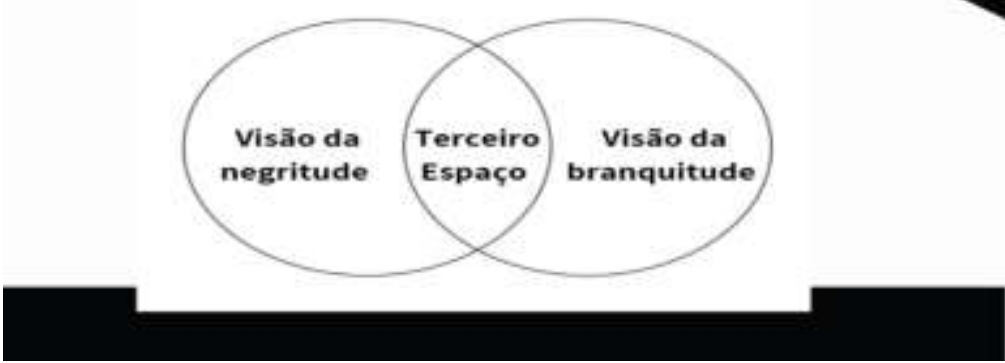

Fonte: Adaptado de BHABHA (1990).

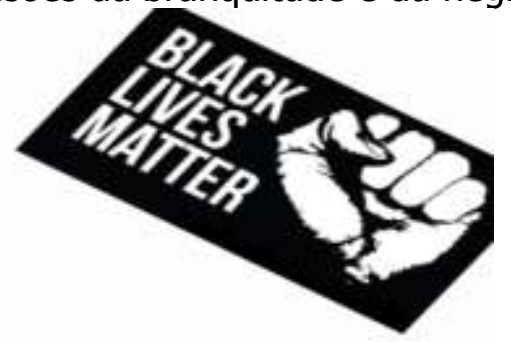

Ferreira (2014) aborda o Letramento Racial $\mathrm{Crítico}^{8}$, que parte da Teoria Racial Crítica ${ }^{9}$, para tratar da identidade racial branca e da identidade racial negra. Por esse caminho, o Letramento Racial tem "uma compreensão poderosa e complexa da forma como a raça influencia as experiências sociais, econômicas, políticas e educacionais dos indivíduos e dos grupos" (SKERRETT, 2011, p. 314). Por isso, Ferreira (2014, p. 250) ressalta que "para termos uma sociedade mais justa e igualitária, temos que mobilizar todas as identidades de raça branca e negra para refletir sobre raça e racismo". A partir dessas reflexões, promover um trabalho crítico no contexto escolar em todas as disciplinas do currículo escolar (FERREIRA, 2014).

\footnotetext{
${ }^{8}$ Esse letramento parte da Teoria Racial Crítica (LADSON-BILLINGS; TATE, 1995), perspectiva usada recentemente no campo educacional, fortemente nos Estados Unidos, para "examinar as experiências de estudantes africano-americanos latinos e, principalmente a intersecção com classe, gênero e sexualidade" (FERREIRA, 2014, p. 242), a branquitude é utilizada para as abordagens sobre raça e racismo, sendo uma "construção social que deveria ser discutida para que as pessoas tivessem a possibilidade de entender a forma como isso foi construído." (FERREIRA, 2014, p. 247).

${ }^{9}$ A Teoria Racial Crítica engloba cinco princípios fundamentais, que são: a "intercentricidade de raça e racismo, o desafio à ideologia dominante, o compromisso com a justiça social, a perspectiva interdisciplinar e a centralidade do conhecimento experiencial" (FERREIRA, 2014, p. 243).
} 
Neste escrito, o intuito é promover a reflexão e a conscientização. A reflexão, segundo Fairclough (2001), pressupõe o entendimento do senso comum como sustentador de relações de poder, manifestadas implícita ou explicitamente nos discursos, porém dificilmente são formuladas ou examinadas conscientemente.

No que se refere à conscientização, Freire (1979) dialoga que

[...] A conscientização implica, pois, que ultrapassemos a esfera espontânea de apreensão da realidade, para chegarmos a uma esfera crítica na qual a realidade se dá como objeto cognoscível e na qual o homem assume uma posição epistemológica (FREIRE, 1979, p. 15).

Assim, na próxima seção, apresentamos uma proposta didático-pedagógica com base na prática social dos movimentos do ambiente virtual para o mundo real \#BlackLivesMatter, com base nos princípios apresentados, e que pretende possibilitar discussões que visem a transformação social na Educação Básica e na comunidade escolar atingida pelas ações realizadas.

\section{Referenciais da Proposta Didático-Pedagógica}

Para o desenvolvimento desta proposta, será abordada uma temática que estabelece relações entre o discurso e a sociedade, assim como reflexões sobre como o mundo real e o virtual estão atrelados com relação às suas ações e aos efeitos sociais delas, como é o caso do Movimento Black Lives Matter, que teve início pelas redes sociais, por meio de uma hashtag, após um acontecimento real, foi disseminada e alimentada no ambiente virtual e causou mobilizações sociais ao redor do mundo.

O referido movimento teve início nos Estados Unidos, porém seus efeitos sociais foram sentidos em várias partes do mundo, inclusive no Brasil. Desse modo, embora o racismo estrutural tenha sido arraigado por processos históricos diferentes nesses dois países, as formas como ele opera nessas sociedades apresentam pontos convergentes. Analisar as construções discursivas circulantes em ambos os países, estabelecendo um paralelo intercultural é uma atividade de reflexão necessária, pois é por meio da linguagem, principalmente, que o racismo se mantém e se perpetua de modo aparentemente "invisível", nos mais diversos contextos sociais (ALMEIDA, 2017).

Assim, este projeto propõe um trabalho crítico que reconfigure a abordagem das questões raciais na escola visando à transformação social por meio da reflexão (FAIRCLOUGH, 2009) e da Conscientização (FREIRE, 1979), promovendo o inédito 
viável $^{10}$ (LIBERALI, 2020), de efeito sistemático e duradouro, que perdure contribuindo com o repensar das estruturas sociais e do rompimento com práticas de racismo estrutural, ainda enraizados em nossa sociedade.

Abaixo, apresentamos a proposta didático pedagógica para alunos do Ensino Médio, possível de ser trabalhada com os três anos, com as adaptações necessárias à série de implementação. As atividades apresentadas foram planejadas para o terceiro ano. Ademais, esta proposta está baseada nos elementos do Modelo tridimensional prática social investigada, prática discursiva e texto (CHOULIARAKI; FAIRCLOUGH, 1999, p. 20) e nos princípios do Letramento Racial Crítico, conforme nossa proposição na tabela abaixo:

Quadro 1 - Princípios para a elaboração de materiais para a Educação Antirracista

\begin{tabular}{|l|l|}
\hline \multicolumn{1}{|c|}{\begin{tabular}{c}
\multicolumn{1}{|c|}{ Princípios para a elaboração de materiais para a Educacao } \\
Antirracista
\end{tabular}} & \multicolumn{1}{c|}{ Autor } \\
\hline Reconhecer a existência do problema racial na sociedade brasileira. & $\begin{array}{l}\text { CAVALLEIRO, } \\
2001\end{array}$ \\
\hline $\begin{array}{l}\text { Promover espaços de reflexão sobre o racismo e seus derivados no } \\
\text { contexto escolar. }\end{array}$ & $\begin{array}{l}\text { CAVALLEIRO, } \\
2001\end{array}$ \\
\hline $\begin{array}{l}\text { Promover oportunidades para o repúdio e a intervenção a qualquer atitude } \\
\text { preconceituosa e discriminatória na sociedade e no espaço escolar. }\end{array}$ & $\begin{array}{l}\text { CAVALLEIRO, } \\
2001\end{array}$ \\
\hline $\begin{array}{l}\text { Desenvolver estratégias de cuidado para que as relações entre negros e } \\
\text { brancos (crianças e adultos) sejam respeitosas. }\end{array}$ & $\begin{array}{l}\text { CAVALLEIRO } \\
\text { (2001) }\end{array}$ \\
\hline $\begin{array}{l}\text { Promover igualdade por meio do reconhecimento e valorização da } \\
\text { diversidade do contexto escolar, encorajando a participação de todos os } \\
\text { atores sociais. }\end{array}$ & $\begin{array}{l}\text { CAVALLEIRO } \\
(2001)\end{array}$ \\
\hline $\begin{array}{l}\text { Privilegiar o ensino crítico da história dos diferentes grupos sociais, étnicos } \\
\text { e raciais que constituem a história brasileira. }\end{array}$ & $\begin{array}{l}\text { CAVALLEIRO, } \\
\text { (2001) }\end{array}$ \\
\hline $\begin{array}{l}\text { Privilegiar materiais que promovam a ruptura com o eurocentrismo dos } \\
\text { currículos escolares, materiais didáticos e práticas de ensino. }\end{array}$ & FERREIRA (2012) \\
\hline
\end{tabular}

${ }^{10} \mathrm{~A}$ autora revisita o conceito freiriano, no contexto de pandemia da Covid-19, para "pensar em possibilidades para ir além daquilo que conhecemos, daquilo que já vivemos, daquilo que pode ser repetido sem reflexão. A situação que vivemos exige que nos coloquemos frente ao contexto com nossa história como uma ferramenta para criar o possível." (LIBERALI, 2020, p. 13). 


\begin{tabular}{|c|c|}
\hline $\begin{array}{l}\text { Privilegiar atividades que promovam a diversidade racial e o estudo da } \\
\text { história e cultura do povo negro. }\end{array}$ & FERREIRA (2012) \\
\hline Promover práticas de reconhecimento positivo da diversidade racial. & FERREIRA (2012) \\
\hline $\begin{array}{l}\text { Elaborar ações que possibilitem o fortalecimento do auto-conceito de } \\
\text { alunos e alunas pertencentes a grupos discriminados. }\end{array}$ & FERREIRA (2012) \\
\hline $\begin{array}{l}\text { Usar estratégias curriculares e pedagógicas voltadas para a justiça social, } \\
\text { visando a eliminar formas de discriminação e opressão tanto individual } \\
\text { quanto institucional. }\end{array}$ & FERREIRA (2012) \\
\hline $\begin{array}{l}\text { Ter o currículo e os discursos que permeiam o contexto escolar como alvo } \\
\text { da análise e avaliação constantes. }\end{array}$ & FERREIRA (2012) \\
\hline $\begin{array}{l}\text { Desenvolver instrumentalização para lidar com as situações de racismo em } \\
\text { sua prática docente (consciência racial crítica). }\end{array}$ & FERREIRA (2014) \\
\hline $\begin{array}{l}\text { Promover práticas que rompam com discursos que fortaleçam a hegemonia } \\
\text { da branquitude. }\end{array}$ & FERREIRA (2014) \\
\hline $\begin{array}{l}\text { Incluir atividades e práticas para desconstruir ideologias que reproduzam } \\
\text { estereótipos e preconceitos. }\end{array}$ & FERREIRA (2014) \\
\hline $\begin{array}{l}\text { Promover práticas que contribuam para o surgimento de identidades mais } \\
\text { comprometidas com a superação histórica das desvantagens. }\end{array}$ & FERREIRA (2014) \\
\hline $\begin{array}{l}\text { Promover atividades que permitam entender o funcionamento das relações } \\
\text { de poder e dos discursos. }\end{array}$ & $\begin{array}{l}\text { PEREIRA; } \\
\text { LACERDA (2019) }\end{array}$ \\
\hline $\begin{array}{l}\text { Promover discussões que visam buscar meios para que uma sociedade mais } \\
\text { justa e igualitária seja possível. }\end{array}$ & $\begin{array}{l}\text { PEREIRA; } \\
\text { LACERDA (2019) }\end{array}$ \\
\hline $\begin{array}{l}\text { Usar princípios do letramento racial crítico: 1) Conscientização sobre as } \\
\text { questões raciais; 2) Conhecimento do papel histórico-cultural e social do } \\
\text { negro para além da escravidão; 3) Reconhecimento da necessidade de } \\
\text { representatividade do povo negro em espaços sociais que ainda lhe são } \\
\text { negados; 4) Problematização do papel do negro na sociedade } \\
\text { contemporânea e as questões de reparação histórica; 5) Racismo } \\
\text { estrutural, institucional e discursos de silenciamento; 6) Planejamento de } \\
\text { ações que visem a desconstruir ideologias estruturadas pela perspectiva da } \\
\text { branquitude e a reconstrução de contextos sociais também favoráveis ao } \\
\text { povo negro. }\end{array}$ & $\begin{array}{l}\text { FERREIRA } \\
\text { (2014). }\end{array}$ \\
\hline $\begin{array}{l}\text { Promover ações de conscientização que promovam o engajamento de } \\
\text { todos os atores sociais do ambiente escolar. }\end{array}$ & FERREIRA (2014) \\
\hline
\end{tabular}

Fonte: Adaptado de Cavalleiro (2001) e Ferreira $(2012,2014)$

\section{Proposta pedagógica}

Nesta seção, apresentamos a proposta pedagógica organizada como uma unidade 
didática que segue os princípios do Letramento Racial Crítico e dos pressupostos da ADC que perpassa a prática social investigada, a prática discursiva e o texto.

Prática Social Investigada: Redes e mobilizações sociais (movimentos do ambiente virtual para o mundo real Black Lives Matter)

Prática Discursiva: Discursos produzidos nas redes sociais, em diferentes gêneros digitais, sobre o movimento Black Lives Matter.

Texto: Uso de construções gramaticais e elementos linguísticos para provocar efeitos de sentido

Objetivos:

1) Relacionar o conhecimento do/a estudante aos acontecimentos sociais amplamente divulgados pelas redes sociais e pela mídia em geral, com os quais ele/ela tem contato rotineiramente, desenvolvendo o letramento crítico para que ele/ela lide e compreenda os fenômenos ideológicos e construções discursivas por trás da informação.

2) Promover a aprendizagem e os letramentos racial e cultural, por meio do estudo, análise, discussões, contato e relatos de experiências advindos de outras culturas presentes no contexto escolar.

Ações Propostas:

1) Pesquisar e discutir sobre a história do povo negro nos dois países para ampliação da pauta dessa população e suas reivindicações por justiça social e reparação histórica na atualidade. Conhecer como a legislação brasileira atuou por brancos e negros ao longo da história.

2) Fomentar reflexões, atividades e discussões fundamentadas (após a realização de pesquisa e conversas) sobre o Movimento Social Black Lives Matter. Questionar o que aproxima e distancia os dois países no tratamento do racismo e em que medida esse movimento reflete as mesmas demandas nos dois territórios.

3) Analisar as construções discursivas presentes em alguns gêneros utilizados nas postagens pelo movimento, visando a compreender os efeitos sociais desses discursos no Brasil e nos Estados Unidos.

Gêneros Abordados:

Infográfico; Postagens de redes sociais; Manchetes de jornais digitais; Webquest; Formulários do Google.

Descrição das atividades:

1) Explorar a vivência dos/as alunos/as e o compartilhamento de 
informações. Familiarização com a temática. O/A professor/a inicia as discussões com a apresentação de diversas imagens de redes sociais sobre o Movimento Black Lives Matter, analisando com os/as estudantes as possíveis maneiras que uma prática social pode ser noticiada e os efeitos construídos no texto que promovem efeitos sociais.

2) Formar grupos para trabalho colaborativo de pesquisa sobre a História do povo negro, sua representação na sociedade atual e o início do Movimento Black Lives Matter. Os/As estudantes seguirão um roteiro norteador e, a partir dele, devem realizar as buscas no ambiente virtual para apresentação durante as discussões com a turma. 0 objetivo desta atividade é esquematizar a estruturação de um Jornal Digital temático, no ambiente escolar, que apresente para a comunidade informações sobre a pauta racial e promova reflexões sobre a temática pelas perspectivas da negritude, da branquitude e da intersecção de ambas por meio do compartilhamento de vivências e conhecimentos durante os espaços de discussões.

3) Os/As estudantes devem analisar as notícias atuais, infográficos e manchetes em inglês e em língua materna sobre as questões étnicoraciais, traçar suas considerações sobre as informações apresentadas, considerando essencialmente as características dos gêneros, no que concerne ao conteúdo temático, estrutura e estilo, além do contexto e condições de produção e circulação, intencionalidade e escolhas discursivas realizadas.

O conteúdo léxico gramatical deve ser estudado considerando sua função no processo de construção de sentidos dentro da prática social observada a partir do texto de referência.

Figura 3 - Possibilidade de trabalho linguístico pelo viés do Letramento Racial Crítico

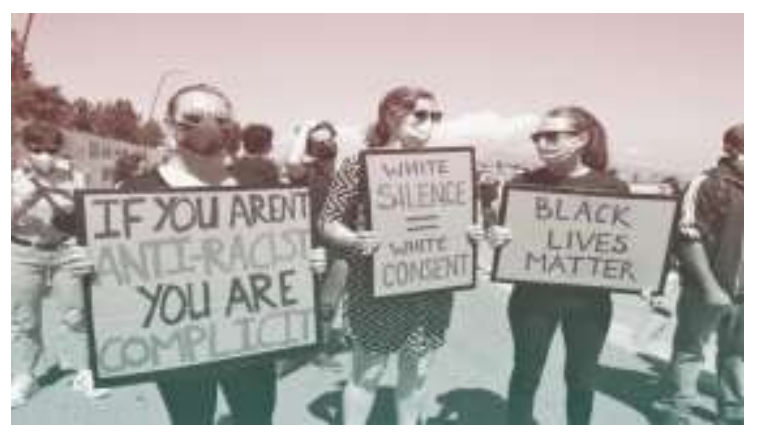

Fonte: Mills (2021).

What is this scenario? What kind of information can we read when we see the context of the picture?

About the racial issues: What is the race of people holding the poster? What is the social meaning of this action?

What are the social and historical contexts in which these posters were created?

What is the intention of the authors of these posters? What are they doing in a black 
rights social movement?

What is the function of the linking word "if" in the sentence in the poster? What kind of sentence is this and when is it used?

What do you think about white people taking part in a black social movement?

What black people complain about? Analyzing Brazilian context, black people suffer with some situations triggered by the color of their skin or do you think we live in a racial democracy?

4) O/A professor/a conduz às seguintes reflexões: $O$ que você entende por identidade racial? A identidade racial é capaz de promover a consciência racial? O que você entende por isso? Você tem conhecimento sobre o que significam os termos "branquitude" e "negritude" em uma perspectiva sócio-histórico-cultural? (Explicar a perspectiva)? Há uma democracia racial no Brasil? A conversa inicial é retomada e a reflexão conduzida após o aprofundamento sobre o assunto por meio da pesquisa. Questões sobre silenciamento, representatividade e identidade racial devem ser norteadoras visando a conscientização e a desconstrução de discursos racistas socialmente estruturados e reproduzidos.

5) Além da criação e manutenção de um veículo de comunicação sobre as questões étnico-raciais na escola durante o ano todo, esta proposta defende a elaboração de um projeto integrador colaborativo pautado nos preceitos da Educação Antirracista. Por meio do projeto, promover a conscientização e a transformação social na comunidade escolar.

\section{Avaliação}

O processo de avaliação será caracterizado pela avaliação formativa, sendo ela processual e gradativa, ou seja, o/a estudante será avaliado/a pela sua contribuição em todas as fases do processo de planejamento, criação, conclusão e divulgação do projeto do jornal digital.

Serão considerados para os procedimentos avaliativos, os seguintes instrumentos e critérios:

- A contribuição do estudante com o grupo de trabalho, monitorada por meio de relatório produzido pelo próprio grupo;

- O material produzido pelo grupo para a composição do Jornal Digital e do Projeto de Conscientização junto à comunidade, em língua inglesa e em língua materna;

- O conhecimento do conteúdo e dos recursos digitais, interações nos ambientes virtuais de aprendizagem, posicionamento crítico e engajamento discursivo nos espaços de discussão, monitorados por meio de suas contribuições orais e suas narrativas escritas;

- A apresentação e qualidade do material coletados durante a pesquisa sobre a temática; 
- Autoavaliação por meio de Formulário do Google considerando a análise do aprendiz sobre sua percepção e participação no processo.

\section{Considerações Finais}

Este artigo teve por objetivo apresentar uma proposta de trabalho com o Letramento Racial Crítico, para estudantes do Ensino Médio da Educação Básica, embasada nos pressupostos do Letramento Racial Crítico e no modelo tridimensional da Análise do Discurso Crítica. Organizada em formato de unidade didática, propusemos a ordenação sequencial das atividades de modo que o aluno vivencie os pressupostos de uma educação antirracista, visto que a necessidade de práticas voltadas para essa perspectiva são urgentes no contexto escolar.

$\mathrm{Na}$ esteira do Letramento Racial Crítico como uma das bases da Educação Antirracista na educação básica, Ferreira (2014) esclarece que esse letramento consiste em questionar, em promover discussões sobre raça. É questionar documentos oficiais e materiais didáticos que continuem a promover a hegemonia branca através de referências eurocêntricas e acabam por silenciar ou reproduzir estereótipos sobre a população negra. É promover novos materiais que reconheçam as identidades raciais presentes no contexto escolar e social brasileiro, de forma que cada um ocupe o espaço que the é devido na estrutura social. É refletir sobre os cursos de formação de professores/as, por exemplo, que identidades esses espaços têm promovido e como ou se as diversidades são contempladas. É analisar como as pessoas negras são representadas nos livros de literatura e pelos discursos que permeiam a escola e a sociedade e qual é o impacto dessas construções na vida e na identidade das pessoas negras.

Desse modo, as discussões sobre as questões raciais na Educação Básica (que são amparadas pelas leis 10.639/03 e 11.645/08) tornam-se essenciais para que mais professores/as e estudantes desenvolvam a consciência racial crítica, constituindo pilares importantes para a promoção da Educação Antirracista.

Acreditamos que propostas como essa têm potencial para contribuir com uma Educação Antirracista e assim avançar àequidade racial pelo fato de que o trabalho com a linguagem permite refletir, desenvolver consciência, avaliar os sistemas de opressão, questionar nossas próprias crenças e experiências e ainda agir na sociedade. Assim, o referencial teórico que nos orienta também nos dá base para realizar um projeto que 
SANTOS, C. G.; SANTOS, J. R. O.; EL KADRI, M. S.

entende que a linguagem tem poder de manter, acirrar ou transformar realidades.

\section{Referências}

ALMEIDA, S. Racismo estrutural: feminismos plurais. São Paulo: Editora Pólen, 2017.

BHABHA, H. K. The third space. In: RUTHERFORD, J. Identity: community, culture, difference. Londres: Lawrence and Wishart, 1990. p. 207-21.

BRASIL. Lei no 10.639 de 09/01/2003. Estabelece as diretrizes e bases da educação nacional, para incluir no currículo oficial da Rede de Ensino a obrigatoriedade da temática. História e Cultura Afro-Brasileira. Diário Oficial da União, Brasília, DF, 10 jan. 2003.

BELL, L. A. Theoretical foundations for social justice education. In: ADAMS, M.; BELL, L.; GRIFFIN, P. (ed.). Teaching for diversity and social justice: a sourcebook. Nova York: Routledge, 1997. p. 3-15.

CAVALLEIRO, E. Educação antirracista: compromisso indispensável para um mundo melhor. In: CAVALLEIRO, E. (org.). Racismo e anti-racismo na educação: repensando nossa escola. São Paulo: Selo Negro, 2001. p. 141-160.

CHOULIARAKI, L.; FAIRCLOUGH, N. Discourse in late modernity: rethinking critical discourse analysis. Edimburgo: Edinburgh University Press, 1999.

GUIMÓN, P. Black lives matter, o rumo incerto do grande movimento antirracista. El País, [São Paulo], 7 set. 2020. Disponível em:

https://brasil.elpais.com/internacional/2020-09-07/black-lives-matter-o-rumo-incertodo-grande-movimento-antirracista.html. Acesso em: 20 de março de 2021.

FAIRCLOUGH, N. Discurso e mudança social. Brasília: Universidade de Brasília, 2009.

FAIRCLOUGH, N. Analysing discourse: textual analysis for social research. Londres: Routledge, 2003.

FAIRCLOUGH, N. Language and power. 2. ed. Nova York: Longman, 2001.

FERREIRA, A. de J. Identidades sociais, letramento visual e letramento crítico: imagens na mídia acerca de raça/etnia. Trabalhos em Linguística Aplicada (UNICAMP),

Campinas, v. 51, p. 193-215, 2012.

FERREIRA, A. de J. Narrativas autobiográficas de professoras/es de línguas na universidade: letramento racial crítico e teoria racial crítica. In: FERREIRA, A. de J. (org.). Narrativas autobiográficas de identidades sociais de raça, gênero, sexualidade e classe em estudos da linguagem. Campinas: Pontes Editores, 2015. v. 1, p. 127-160.

FERREIRA, A. de J. Teoria racial crítica e letramento racial crítico: narrativas e contranarrativas de identidade racial de professores de línguas. Revista da ABPNI, Guarulhos, v. 6 , n. 14, p. 236-263, jul./out. 2014. 
FERREIRA, A. de J. What has race/ethnicity got to do with EFL teaching? Linguagem e Ensino, Pelotas, v. 10, n. 1, p. 211-233, 2007.

FERREIRA, A. de J.; BARBOSA, A. Entrevista com Aparecida de Jesus Ferreira. Revista $X$, Curitiba, v. 14 , n. 3, p. 1-15, 2019.

FREIRE, P. Conscientização: teoria e prática da libertação: uma introdução ao pensamento de Paulo Freire. São Paulo: Cortez \& Moraes, 1979.

GONÇALVES, L. A. O.; SILVA, P. B. G. e. O jogo das diferenças. o multiculturalismo e seus contextos. Belo Horizonte: Autêntica, 1985.

LEFFA, V. J. Aspectos políticos da formação do professor de línguas estrangeiras. In: LEFFA, V. J. (org.). O professor de línguas estrangeiras. construindo a profissão. Pelotas: Educat, 2008. v. 1, p. 333-355.

LIBERALI, F. C. Construir o inédito viável em meio à crise do coronavírus - lições que aprendemos, vivemos e propomos. In: LIBERALLI, F. C. et al. (org.) Educação em tempos de pandemia: brincando com um mundo possível. Campinas: Pontes Editores, 2020. p. $13-21$.

MILLS, M. The many ways white parents benefit from white privilege - and how that can change. Parents, [s. l., 2021]. Disponível em:

https://www.parents.com/kids/responsibility/racism/the-many-ways-white-parentsbenefit-from-privilege-and-how-that-can-change/. Acesso em: 20 de março de 2021.

MOSLEY, M. 'That really hit me hard': moving beyond passive anti-racism to engage with critical race literacy pedagogy. Race Ethnicity and Education, [s. I.], v. 13, n. 4, p. 449-471, 2010.

PEREIRA, A. L.; LACERDA, S. S. P. de. Letramento racial crítico: uma narrativa autobiográfica. Travessias, Cascavel, v. 13. n. 3. p. 90-106. set./dez. 2019.

PIZA, E. Adolescência e racismo: uma breve reflexão. In: SIMPÓSIO INTERNACIONAL DO ADOLESCENTE, 1., 2005, São Paulo. Anais eletrônicos [...]. São Paulo: USP, 2005. Disponível em:

http://www.proceedings.scielo.br/scielo.php?pid=MSC0000000082005000100022\&scrip $\mathrm{t}=\mathrm{sci}$ arttext. Acesso em: 13 ja. 2021.

RESENDE, V. de M.; RAMALHO, V. Análise de discurso crítica, do modelo tridimensional à articulação entre práticas: implicações teórico-metodológicas. Linguagem em (Dis)curso - LemD, Tubarão, v. 5, n. 1, p. 185-207, jul./dez. 2004.

RESENDE, V. de M.; RAMALHO, V. Análise de discurso crítica. São Paulo: Contexto, 2006.

RIBEIRO, D. O que é lugar de fala?. Belo Horizonte: Letramento, 2017.

SILVA, E. R. da; GONÇALVES, C. A. Possibilidades de incorporação da análise crítica do discurso de Norman Fairclough no estudo das organizações. Cadernos EBAPE.BR, Rio 
de Janeiro, v. 15, n. 1, p. 1-20, 2017.

SKERRETT, A. English teachers' racial literacy knowledge and practice. Race Ethnicity and Education, [S. I.], v. 14, n. 3, p. 313-330, 2011.

SOARES, J. F.; ALVES, M. T. G. Desigualdades raciais no sistema brasileiro de educação básica. Educação e Pesquisa, São Paulo, v. 29, n. 1, p. 147-165, jan./jun. 2003

WODAK, R. Do que trata a ACD - um resumo de sua história, conceitos importantes e seus desenvolvimentos. Revista Linguagem em (Dis)curso, Florianópolis, v. 4, p. 223243, 2004 Número especial.

Submetido em: 24 mar. 2021. Aceito em: 07 jul. 2021. 